\title{
Comparative Study of Treatment of Trigger Points Pain With Two Techniques .1 Muscle Energy Technique Alone 2. Combined Approach
}

\author{
Dr Rabiya Noor ${ }^{1}$, Dr. Muhammad Salman Bashir ${ }^{2}$, Dr. Binash Afzal ${ }^{3}$ \\ ${ }^{1}$ Assistant Professor, Imperial College of business studies, Lahore. Pakistan \\ ${ }^{2}$ Associate Professor, Imperial College of business studies, Lahore. Pakistan \\ ${ }^{3}$ Clinical Physiotherapist, Shalimar Hospital, Lahore. Pakistan
}

\begin{abstract}
Objective: To compare efficacy of Muscle energy technique alone, and combination of Muscle energy Technique with stretching in treatment of Trigger point pain of cervical muscle in terms of pain reduction, and Neck Disability Index. Methods: Fourty patients with age 18 _40 years having non-specific neck pain with trigger points in either upper trapezius levator scapulae and sternocleidomastoid trigger points were taken from the phyical therapy department of Shalamar hospital Lahore. Patients were randomized into two groups, One group received Muscle energy techniques while the second group received an integrated or combined approach consisting of muscle energy techniques and passive stretching. Each manure was repeated for three to five times per treatment session 3 days in a week for 4 consecutive weeks. After 4 week patients were reassessed for improvement in neck disability index and reduction in pain on visual analogue scale. Results: The results showed that The P-value for neck disability index NDI in group B using combined approach was 0.000 and for VAS was 0.002 which is less than the level of significance 0.005 . So the findings of this study indicated that combined approach (MET with stretching) is more effective in deactivation of trigger points pain in term of reducing pain, and improving neck disability index. Conclusion: It was concluded that combination of muscle energy technique with stretching is more effective than Muscle energy technique alone for patients with trigger point pain.
\end{abstract}

Keywords: Muscle Energy Technique, Neck Disability Index, Trigger point, Stretching, Patients

\section{Introduction}

Neck pain is widely spread disorder and its prevalence ids $54 \%$ in 6 months.(1) moreover this problem also effects the economy as neck pain can lead to permanent posture problems which further induce pain.(2) Most of the time the cause is not specific.(3) but a lot of factors can contribute in it, one of them is presence of trigger points. Research says that trigger points (TrPs) form due to misaligned posture in which muscles receive overloading which cause injury to muscle fibers.(4) The injured fibers receive less oxygen and blood supply which leads to less removal of metabolic waste as well as supply of nutrients to muscle fibers .This leads to formation of trigger points.(5)

TrPs cause hyperalgesia which limit ranges of neck and restrict activities of daily life (ADLs). It is identified on the basis of physical examination and presence of typicalsigns which are associated with $\operatorname{TrPs}(6)$ There is a tight band of skeletal muscle which cause tenderness. This band can be palpate on physical examination and patient give jump sign when therapist grasps this band in his hand. Patient may complain referral pain. $(7,8)$

To treat trigger points manual and non manual both protocols are used. It includes boutlin toxins and muscle relaxant drugs as well as Muscle energy techniques (METs), myofacial release etc.(9) METs is effective treatment for TrPs.(10) It is used for decreasing tone of muscle before stretching. It includes isometric contraction of muscle which induces post relaxation by autogenic inhibition. Reciprocal inhibition also used $(11,12)$
Ischemic compression technique is mostly used; in this a constant pressure applied on affected muscle by digits. It slows down the blood supply there and decrease the pain, when pressure is released blood rushed towards muscle and waste material remove from there.Pain relief also because of hyperemia.(13)Strain counter strain (SCS) is another manual approach in which pressure is applied on effected area and then positioned in which tension is less on muscle. It gives relaxation to the muscle (14)Chaitow researched that combination of both techniques is more beneficial in treatment of trigger points. This is known as integrated neuromuscularinhibition technique (INIT).(15)

Albert Atienza Meseguer, et al conducted a study to find out immediate effect of a conventional and a advanced strain/counterstrain techniques, in reducing pain pressure threshold(PPT), after only one treatment session of trapezius tender point. Following either conventional or advanced strain/counterstrain technique there were significant reduction in pain on the visual analogue scale of pain with $(\mathrm{P}<$ 0.001).). They drew conclusion then that strain/counterstrain was effective for tender points by reducing their pain of upper trapezius muscle.(16)

Hugh Gemmell, et al in their study had taken the patients with nonspecific cervical pain having upper trapezius trigger point and studied the immediate effect of deep pressure method such as by ischemic compression, trigger point pressur pincer grip method or release and placebo ultrasound on pain, degree of neck side bending and pain pressure threshold(PPT). They concluded that ischemic compression is far better than sham ultrasound reducing pain.(17) 


\section{International Journal of Science and Research (IJSR) \\ ISSN (Online): 2319-7064 \\ Index Copernicus Value (2013): 6.14 | Impact Factor (2015): 6.391}

Amit V Nagrale, et al. the purpose of this clinical trial was to compare the effectiveness of a combination approach named as integrated including three techniques in it which were muscle energy techniques(MET), ischemic compression (IC), and strain-counterstrain (SCS). this study vividly exhibit that integrated approach is much more better than MET alone in deactivation of trigger point pain.(18)

\section{Material and Methods}

\section{Study Design}

Randomized clinical trial study design was used.

\section{Settings}

Data was collected from Shalimar hospital Lahore.

\section{Duration of Study}

Study was completed in four months from October 2014 to January 2014.

\section{Sampling Technique}

Purposive sampling was used to get the sample.

\section{Target Population}

Patients who presented with non-specific, non-articular neck pain.

\section{Sample Size}

A total sample size of 40 patients, 2 study groups was made 20 patients will be taken in each group .Groups assigned randomly.

\section{Inclusion Criteria}

1. All the patients having age 18 to 40 years with either gender.

2. Male female both are included in this study. Number of trigger point maximum 2 .

3. Unilateral trigger point.

4. Patients with non-articular and nonsystematic neck pain.

\section{Exclusion Criteria}

Patients were excluded

1. if neck symptoms will be related to a motor vehicle collision or significant trauma,(whiplash injury).

2. if there will be signs of serious pathology (e.g. malignancy, infection, inflammatory disorder, or fracture),

3. if there were be signs of cervical spinal cord compromise (e.g. diffuse sensory abnormality, diffuse weakness, hyperreflexia, or the presence of clonus).

\section{Study Groups}

\section{Group A:}

In this group included patients received Muscle Energy Technique maneuver on trapezius muscle having trigger point, in which post isometric relaxation method of MET was used.

\section{Group B:}

Patients in group B received combined approach consisting on METs and SCS.

\section{Muscle energy technique group}

The patients who were in this group treated in such a manner that patients were placed supine and stabilized the shoulder on effected side with one hand and other hand stabilized the head and give gentle pressure and head move towards opposite side and then flexed, rotate towards effected side to contract upper trapezius band which cause restriction in ROM. Then ask the patient to try to touch your ear with elevated shoulder in pain free range and hold for 5 to 10 seconds. Therapist sustained stretch for 30 seconds. (19, 20)

\section{Integrated neuromuscular inhibition techniquegroup or combined approach}

After the identification of TrPs by pincer grasp method INIT was applied on patient. In first session therapist grasp the band in between index finger and thumb and gradually pressure increases so barrier of muscle reached. Pressure sustained until it disappears under ur grip pressure continues further to reach the next barrier.

Than SCS technique was used on same patient. In this patient filled VAS scale prior to treatment and rate his pain on scale 1 to 10 . If the pain is not produced then further pressures was applied and then leave the muscle in relaxed position. In last of the treatment session patient received METs (21). Each manure was repeated for three to five times per treatment session 3 days in a week for 4 consecutive weeks.

\section{Data analysis}

The data will be analyzed by using the SPSS 18.0 statistical software. Baseline characteristics including means and standard deviations (SD) will be described. The mean differences with SD for the outcome measures of pain, and neck disability will be calculated for the time periods of baseline to 2 weeks, and baseline to 4 weeks. Independent $t$ test will be used to test the hypothesis and to find out the difference between the groups and paired t test will be used for pre and post score of VAS, NDI within the groups at each follow-up period. Level of significance is 0.05 . A onetailed hypothesis is generated favoring the MET with stretching group. The minimum required sample size will be 20 subjects per group.

\section{Results}

50 patients were screened for eligibility. Ten subjects failed to meet the criteria for study participation .fourty patients were participating in the study .20 patients were randomized to receive METs, with mean age 35.2 years (SD = 8.25years), and 20 subjects received combined approach, with mean age 34.5 years ( $\mathrm{SD}=9.03$ years). All 40 patients completed the study and were included in the analysis. The baseline characteristics were found to be similar between groups

\section{Baseline characteristics of the sample}

20 patients assigned group A received METs, showed mean score of neck pain disability index before treatment 24.9500 $(\mathrm{SD}=5.633)$, and mean pain score on VAS before treatment5.8500 (SD = 2.007). where as 20 patients in group of INIT, had mean score of neck pain disability 


\section{International Journal of Science and Research (IJSR) ISSN (Online): 2319-7064 \\ Index Copernicus Value (2013): 6.14 | Impact Factor (2015): 6.391}

index before treatment , 25.150 (SD = 4.602), and mean pain score on VAS before treatment $5.600(\mathrm{SD}=2.18307$. so there was no significant difference in mean and standard deviation of pain and NDI scores in baseline readings.

\section{Between-group change scores from baseline after 4 weeks}

Group A , showed mean score of neck pain disability index after MET treatment $9.5500(\mathrm{SD}=2.799)$, and mean pain score on VAS 2.350 (SD = 1.08942). where as patients in group of INIT, showed mean score of neck pain disability index after with combined therapy treatment 4.000 (SD = 1.3764), and mean pain score on VAS before treatment was 1.1500 (SD $=1.1367$. As in case of NDI the standard deviations for the two groups are similar (0.69765), we will use the "equal variances assumed" test. The results indicate that there is a statistically significant difference between the mean NDI post treatment score and NDI pretreatment score $(\mathrm{t}=7.955, \mathrm{p}=.000)$. As $\mathrm{p}=.000$ is less than $\mathrm{p}=.05$ so we will reject our null hypothesis and accept alternative hypothesis.For VAS standard deviations for the two groups are similar (.35206), researcher use the "equal variances assumed" test. The results indicate that there is a statistically significant difference between the mean VAS post treatment score and VAS pretreatment score $(\mathrm{t}=3.408$, $\mathrm{p}=.002$ ). As $\mathrm{p}=.002$ is less than $\mathrm{p}=.05$ so we will reject our null hypothesis and accept alternative hypothesis.

\begin{tabular}{|c|c|c|c|c|c|}
\hline \multicolumn{9}{|c|}{ GROUP STATISTICS } \\
\hline & Group & $\mathrm{N}$ & Mean & Std. Deviation & Std. Error Mean \\
\hline \multirow{2}{*}{$\begin{array}{c}\text { Score of neck pain disability } \\
\text { index before treatment }\end{array}$} & Group A ( Muscle energy technique) & 20 & 24.9500 & 5.63331 & 1.25965 \\
\cline { 2 - 6 } & Group B( INIT) & 20 & 25.1500 & 4.60292 & 1.02924 \\
\hline \multirow{2}{*}{ NDI.score.post } & Group A ( Muscle energy technique) & 20 & 9.5500 & 2.79991 & .62608 \\
\cline { 2 - 6 } & Group B( INIT) & 20 & 4.0000 & 1.37649 & .30779 \\
\hline \multirow{2}{*}{$\begin{array}{c}\text { Pain on VAS scale before } \\
\text { treatment }\end{array}$} & Group A ( Muscle energy technique) & 20 & 5.8500 & 2.00722 & .44883 \\
\cline { 2 - 6 } & Group B( INIT) & 20 & 5.6500 & 2.18307 & .48815 \\
\hline \multirow{2}{*}{\begin{tabular}{c} 
Pain on VAS after Treatment \\
\cline { 2 - 6 }
\end{tabular}} & Group A ( Muscle energy technique) & 20 & 2.3500 & 1.08942 & .24360 \\
\cline { 2 - 6 } & Group B( INIT) & 20 & 1.1500 & 1.13671 & .25418 \\
\hline
\end{tabular}

Group 2: Independent Samples Test

\begin{tabular}{|c|c|c|c|c|c|c|c|c|c|c|}
\hline & \multicolumn{2}{|c|}{$\begin{array}{c}\text { Levene's Test for } \\
\text { Equality of } \\
\text { Variances } \\
\end{array}$} & \multicolumn{5}{|c|}{ t-test for Equality of Means } & \multirow{2}{*}{\multicolumn{2}{|c|}{$\begin{array}{c}\text { 95\% Confidence Interval } \\
\text { of the Difference }\end{array}$}} \\
\hline & & \multirow[t]{2}{*}{$\mathrm{F}$} & \multirow[t]{2}{*}{ Sig. } & \multirow[t]{2}{*}{$\mathrm{T}$} & \multirow[t]{2}{*}{ Df } & \multirow[t]{2}{*}{$\begin{array}{l}\text { Sig. (2- } \\
\text { tailed) }\end{array}$} & \multirow[t]{2}{*}{$\begin{array}{c}\text { Mean } \\
\text { Difference }\end{array}$} & \multirow[t]{2}{*}{$\begin{array}{l}\text { Std. Error } \\
\text { Difference }\end{array}$} & & \\
\hline & & & & & & & & & Lower & Upper \\
\hline \multirow{2}{*}{ NDI.score.post } & $\begin{array}{l}\text { Equal variances } \\
\text { assumed }\end{array}$ & 13.704 & 0.001 & 7.955 & 38 & 0 & 5.55 & 0.69765 & 4.13769 & 6.96231 \\
\hline & $\begin{array}{l}\text { Equal variances } \\
\text { not assumed }\end{array}$ & & & 7.955 & 27.677 & 0 & 5.55 & 0.69765 & 4.12019 & 6.97981 \\
\hline \multirow{2}{*}{$\begin{array}{c}\text { Pain on VAS } \\
\text { after } \\
\text { Treatment }\end{array}$} & $\begin{array}{l}\text { Equal variances } \\
\text { assumed }\end{array}$ & 1.102 & 0.3 & 3.408 & 38 & 0.002 & 1.2 & 0.35206 & 0.48729 & 1.91271 \\
\hline & $\begin{array}{l}\text { Equal variances } \\
\text { not assumed }\end{array}$ & & & 3.408 & 37.932 & 0.002 & 1.2 & 0.35206 & 0.48725 & 1.91275 \\
\hline
\end{tabular}

\section{Discussions}

Purpose of this study was to compare muscle energy technique alone and combined effects of muscle energy technique along with stretching in deactivation of trigger point. Results of study indicates that METs may be a viable option for addressing active TrPs in the upper trapezius, lavatory scapulae and SCM ; however, the addition of passive stretching to the METs, produced significantly greater results40 patients with trigger points were divided into two equal groups.in group 1 muscle energy technique was applied and in group 2 INIT was applied.

Neck disability index and baseline questionnaire was used to assess the patient before and after treatment. Neck disability index score was compared in both groups before and after treatment. Mean score of group 1 for NDI was 24.9500 and group 2 was 25.15500.both mean scores showed that patients in group A and group B had approximate same disability. Group A score was decreased from 24.9500 to 9.5500 and group B score was decreased from 25.1550 to 4.000 after treatment. Both of group showed decrease in mean score but group B had a significant decrease. So it proved that intervention given to group $B$ is more effective than intervention given to group $\mathrm{A}$.

In this study, VAS was also used to assess the patients before and after treatment. Group A mean score was reduced from 5.8500 to 2.3500 and group B score was reduced from 5.6500 to 1.1500 after treatment. It also proved that group B improved more than group A. So muscle energy technique and stretching was proved more effective in reducing pain and improving neck disability index than muscle energy technique alone. 


\section{International Journal of Science and Research (IJSR) \\ ISSN (Online): 2319-7064}

Index Copernicus Value (2013): 6.14 | Impact Factor (2015): 6.391

T-test was used to statistically analysis results. T-test result indicate that there was a statistically significant difference between the mean NDI post treatment score and NDI pretreatment score $(\mathrm{t}=7.955, \mathrm{p}=.000)$. As $\mathrm{p}=.000$ is less than $\mathrm{p}=.05$ so we will reject our null hypothesis and accept alternative hypothesis.

T-test was also performed for vas score. The standard deviations for the two groups are similar (.35206), we used the "equal variances assumed" test. The results indicated that there was a statistically significant difference between the mean VAS post treatment score and VAS pretreatment score $(\mathrm{t}=3.408, \mathrm{p}=.002)$. As $\mathrm{p}=.002$ is less than $\mathrm{p}=.05$ so we rejected our null hypothesis and accept alternative hypothesis. So so muscle energy technique and stretching was proved more effective in reducing pain and improving neck disability index than muscle energy technique alone.

Study also reveals some other factors related to trigger point.60\% sufferers of trigger points were females.30-40 year's age group was most effected by trigger points. Mean age was 35.05.in my study, 35.7 cases were reported from lower class.52.5\% had sedentary life style.35\% were smokers. One important factor was that $42.5 \%$ patient had computer usage history.57.5\% cases reported had limited ROM at neck.60 \% patient had stress history so it may be a risk factor in development of trigger point. $42.5 \%$ cases had impaired sleep pattern in which $30 \%$ had less than 6 hours sleep.

The benefit of the Combined approach over MET may be due to addition of stretching which ultimately causes the lengthening of sarcomere as trigger point are formed due to shrinkage of sarcomere in the involved muscle fibers so consequently by lengthening of muscle fiber it decrease the pain secondly tissue relaxation created by passive stretching and MET in combination facilitating 'reduction of tone in the tissues involved. This reduction in local tone further results in modification of neural reporting and improved local circulation. These changes ultimately facilitate a resetting of the neural reporting structures, resulting in a more normal resting length, enhanced circulation, and decreased pain.

Studies showed that ultrasound and ischemic compression on trigger points reduces the basal electrical activity of muscle but ischemic contraction is more effective.

\section{Conclusion}

In patients with non-specific neck pain, combined approach using both MET, stretching,strain counter strain effect and ischemic compression for the treatment of TrPs has proven to be more beneficial in relieving pain, and improving neck disability index as compared to METs in isolation. The results of this clinical trial contribute to the growing body of evidence supporting the use of manual physical therapy in individuals with active TrPs. Further research is warranted with variable competing interventions such as cervical and thoracic thrust manipulations. Longer follow-up periods are recommended as well as the investigation of whether the combined approach produces clinically meaningful outcomes.

\section{References}

[1] Douglass AB, Bope ET. Evaluation and treatment of posterior neck pain in family practice. The Journal of the American Board of Family Practice. 2004;17(suppl 1):S13-S22.

[2] Côté P, Cassidy JD, Carroll LJ, Kristman V. The annual incidence and course of neck pain in the general population: a population-based cohort study. Pain. 2004;112(3):267-73.

[3] Borghouts JA, Koes BW, Bouter LM. The clinical course and prognostic factors of non-specific neck pain: a systematic review. Pain. 1998;77(1):1-13.

[4] Mense S, Simons DG, Russell IJ. Muscle pain: understanding its nature, diagnosis, and treatment: Lippincott Williams \& Wilkins; 2001.

[5] Newman DIL. Myofascial Pain and Dysfunction: The Trigger Point Manual; The Lower Extremities. The Clinical Journal of Pain. 1992;8(2):178.

[6] Harden RN, Bruehl SP, Gass S, Niemiec C, Barbick B. Signs and symptoms of the myofascial pain syndrome: a national survey of pain management providers. The Clinical Journal of Pain. 2000;16(1):64-72.

[7] Simons DG. Clinical and etiological update of myofascial pain from trigger points. Journal of Musculoskelatal Pain. 1996;4(1-2):93-122.

[8] de las Penas CF, Sohrbeck Campo M, Fernández Carnero J, Miangolarra Page JC. Manual therapies in myofascial trigger point treatment: A systematic review. Journal of Bodywork and Movement Therapies. 2005;9(1):27-34.

[9] Alvarez DJ, Rockwell PG. Trigger points: diagnosis and management. American family physician. 2002;65(4):653-62.

[10] Chaitow L. Muscle energy techniques: Elsevier Health Sciences; 2006.

[11] Niel-Asher S. The concise book of trigger points: North Atlantic Books; 2008.

[12] Ward RC, Association AO. Foundations for osteopathic medicine: Lippincott Williams \& Wilkins; 2003.

[13] Hou C-R, Tsai L-C, Cheng K-F, Chung K-C, Hong CZ. Immediate effects of various physical therapeutic modalities on cervical myofascial pain and trigger-point sensitivity. Archives of physical medicine and rehabilitation. 2002;83(10):1406-14.

[14] Vernon H, Schneider M. Chiropractic management of myofascial trigger points and myofascial pain syndrome: a systematic review of the literature. Journal of manipulative and physiological therapeutics. 2009;32(1):14-24.

[15] Chaitow L. Modern neuromuscular techniques: Elsevier Health Sciences; 2010.

[16] Albert AM, César F, L. J. Immediate effects of the strain/counterstrain technique in local pain evoked by tender points in the upper trapezius muscle. Clinical Chiropractic 2006;9(3):112-8.

[17] Hugh G, Peter M, N. H. Immediate effect of ischaemic compression and trigger point pressure release on neck pain and upper trapezius trigger points: A randomised controlled trial, . Clinical Chiropractic an international journal. 2008;11(1):30-6.

[18] Amit V. The efficacy of an integrated neuromuscular inhibition technique on upper trapezius trigger points in 


\section{International Journal of Science and Research (IJSR) \\ ISSN (Online): 2319-7064 \\ Index Copernicus Value (2013): 6.14 | Impact Factor (2015): 6.391}

subjects with non-specific neck pain: a randomized controlled trial. J Man Manip Ther. 2010;18(1):37-43.

[19] Smith M, Fryer G. A comparison of two muscle energy techniques for increasing flexibility of the hamstring muscle group. Journal of Bodywork and Movement Therapies. 2008;12(4):312-7.

[20] Simons DG, Travell JG, Simons LS. Travell \& Simons' myofascial pain and dysfunction: upper half of body: Lippincott Williams \& Wilkins; 1999.

[21] Moher D, Schulz KF, Altman DG. The CONSORT statement: revised recommendations for improving the quality of reports of parallel group randomized trials. BMC Medical Research Methodology. 2001;1(1):2. 